\title{
PENGARUH PEMBERIAN REWARD TERHADAP MOTIVASI BELAJAR SISWA PADA PEMBELAJARAN IPS DI SMPI NURUL YAQIN BUJUR TIMUR BATU MARMAR PAMEKASAN
}

\author{
Siti Zainab \\ Fakultas Tarbiyah, Program Studi Tadris IImu Pengetahuan sosial IAIN Madura \\ izasankperindu@gmail.com \\ Agoes Kamaroellah \\ Fakultas Tarbiyah, Program Studi Tadris IImu Pengetahuan sosial IAIN Madura \\ agoeskamaroellah.stain@gmail.com
}

\begin{abstract}
Abstrak
Pengaruh pemberian Reward terhadap Motivasi belajar siswa pada pembelajaran IPS di SMP Islam Nurul Yaqin Bujur Timur Batu Marmar Pamekasan. Tujuan penelitian ini untuk mengetahui ada tidaknya pengaruh pemberian Reward terhadap Motivasi belajar siswa pada pembelajaran IPS dan seberapa besar pengaruh pemberian Reward terhadap Motivasi belajar siswa pada pembelajaran IPS. Penelitian ini merupakan penelitian populasi (Populasi Research) yaitu seluruh siswa-siswi SMPI Nurul Yaqin yang berjumlah 45 orang. Metode yang digunakan yaitu dengan pendekatan kuantitatif artinya dalam penelitian ini analisis data yang digunakan adalah analisis data statistik yang sifatnya Korelasional yaitu mencari hubungan antara variabel satu dengan variabel lainnya. Pengumpulan data dalam penelitian ini dengan menggunakan angket, observasi dan dokumentasi, dari pengumpulan data yang didapat melalui angket dianalisis secara manual dengan mengunakan analisis Product Moment adalah salah satu teknik untuk mencari korelasi antara dua variabel yang kerap kali digunakan. Sehingga hasil data menunjukka adanya pengaruh pemberian Reward terhadap Motivasi belajar siswa pada pembelajaran IPS.
\end{abstract}

Kata Kunci : Pemberian Reward, Motivasi, dan Pembelajaran IPS

\begin{abstract}
The Effect of Rewarding on Student Motivation in Social Studies learning at Islamic Middle School Nurul Yaqin East Longitude Batu Marmar Pamekasan. The purpose of this study was to determine whether there was an effect of rewards on students' learning motivation in social studies learning and how much influence the rewards on student learning motivation in social studies learning. This research is a population research (Population Research) that is all students of SMPI Nurul Yaqin, amounting to 45 people. The method used is a quantitative approach which means that in this study the analysis of the data used is the analysis of statistical data which is correlational in nature that is looking for a relationship between one variable with another variable. Data collection in this study using a questionnaire, observation and documentation, from the data collection obtained through a questionnaire analyzed manually using Product Moment analysis is one technique to look for correlations between two variables that are often used. So the results of the data show the influence of giving rewards to students' learning motivation in social studies learning.
\end{abstract}

Keyword: Giving Reward, Motivation, and Social Studies Learning 


\section{PENDAHULUAN}

Pendidikan adalah upaya untuk mengembangkan, mendorong, dan mengajak manusia agar tampil lebih Progresif, berdasarkan pada nilai yang tinggi dan kehidupan yang mulia agar terbentuk pribadi yang sempurna, baik yang berkaitan dengan akal, perasaan, maupun perbuatan. Proses kependidikan jelas merupakan usaha untuk membimbing, membina, dan mengarahkan potensi hidup manusia yang berupaya memiliki kemampuan dasar sehingga memiliki prinsip hidup yang lebih matang. ${ }^{1}$

Belajar pada hakikatnya adalah proses interaksi terhadap semua situasi yang ada disekitar individu. Belajar dapat dipandang sebagai proses yang diarahkan pada tujuan dan proses berbuat melalui berbagai pengalaman. Belajar merupakan proses melihat, mengamati dan memahami sesuatu. Kegiatan pembelajaran dilakukan oleh dua orang pelaku, yaitu guru dan siswa. Perilaku guru adalah mengajar dan perilaku siswa adalah belajar. Perilaku mengajar dan perilaku belajar tersebut terkait dengan bahan pembelajaran. Bahan pembelajaran dapat berupa pengetahuan, nilai-nilai kesusilaan, seni, agama, sikap dan keterampilan. Hubungan antara guru, siswa dan bahan ajar bersifat dinamis dan kompleks, untuk mencapai keberhasilan dalam kegiatan pembelajaran, terdapat beberapa komponen yang dapat menunjang, yaitu komponen tujuan, komponen materi, komponen strategi belajar mengajar dan komponen evaluasi. Masing-masing komponen tersebut saling terkait dan saling mempengaruhi satu sama lain. $^{2}$

Dalam proses pembelajaran sering kali guru menemukan siswa yang merasa jenuh atau bosan untuk belajar di waktu kegiatan belajar mengajar berlangsung, disebabkan karena dalam proses pembelajarannya itu tidak ada yang membuat siswa tersebut semangat untuk belajar, sehingga hal tersebut akan menyebabkan kurang aktifnya siswa dalam proses pembelajaran.

Guru sebagai aktor utama yang berperan mengendalikan jalan proses pembelajaran di dalam kelas diharapkan mampu mengemban tugasnya dengan sebaikbaiknya serta dapat memperbaiki moral siswa dan memotivasi siswa. Dalam hal ini guru memiliki kekuasaan untuk membentuk dan

\footnotetext{
${ }^{1}$ Muhammad takdir llahi, Revitalisasi Pendidikan Berbasis Moral, (Jogjakarta: Ar-Ruzz Media, 2012) HIm. 27-29

2 Rusman, Model-model Pembelajaran, (Jakarta: Rajawali Pers, 2014) HIm. 1
}

membangun kepribadian anak didik sehingga menjadi orang yang berguna bagi agama, nusa dan bangsa. Dalam pengertian sederhana guru adalah orang yang memberikan ilmu pengetahuan kepada anak didik. Selain itu seorang guru juga membutuhkan keterampilan mengajar yang lebih dibanding dengan orang yang bukan guru. Guru harus kaya metode dan strategi mengajar. ${ }^{3}$

Rendahnya Motivasi belajar siswa adalah tantangan bagi seorang guru untuk bisa membangkitkan kembali Motivasi belajar siswa agar tercapai tujuan pendidikan Nasional. Dalam hal tersebut salah satunya harus dilakukan dalam pembelajaran IPS. Karena pembelajaran IPS merupakan salah satu mata pelajaran yang terintegrasi dari ilmu sosial dan humaniora. Disekolah IPS terdiri dari pelajaran Sosiologi, Sejarah, Ekonomi, dan Geografi. Dari empat ilmu tersebut perlu adanya dorongan dari seorang guru karena keterpaduan dari pembelajaran IPS. Hal ini berlandaskan pada hasil observasi dengan guru IPS di SMPI Nurul Yaqin bahwa pembelajaran IPS Ini sangat sulit untuk dipahami karena terpadunya dari berbagai ilmu. Maka dalam mengajarnya tersebut harus ada antusiasme salah satunya dengan menerapkan strategi yaitu pemberian Reward, sehingga dengan hal tersebut siswa memiliki motivasi, karena Motivasi adalah suatu perubahan energy di dalam pribadi seseorang yang ditandai dengan timbulnya afektif dan reaksi untuk mencapai tujuan. ${ }^{4}$

Pemberian rangsangan dari guru seperti pemberian Reward, dimana Reward merupakan salah satu alat untuk meningkatkan Motivasi para peserta didik. ${ }^{5}$ Hal ini akan sangat mempengaruhi Motivasi belajar siswa pada pembelajaran IPS karena melihat ciri dari pembelajaran IPS yaitu Baha pelajarannya akan lebih banyak memperhatikan minat para siswa, maka dalam hal ini yang diharapkan dalam diri siswa akan tumbuh Motivasi untuk berubah menjadi yang lebih baik dan mampu berkompetisi dengan siswa lain sehingga semangat dalam menerima pembelajaran. Untuk bisa mencapai semua itu diperlukan suatu strategi yang bisa memotivasi siswa untuk belajar yaitu strategi yang tepat oleh guru saat mengajar.

\footnotetext{
${ }^{3}$ Rudi Hartono, Ragam Model Mengajar yang Mudah Diterima Murid (Jogjakarta: Diva Press, 2014) hlm. 10

${ }^{4} \mathrm{H}$. M. Muchlis Solichin, Psikologi Pendidikan Berparadigma Konstruktivistik, (Surabaya: CV Salsabila Putra Pratama, 2016) HIm. 107

${ }^{5}$ Kompri, Motivasi Pembelajaran Perspektif Guru dan Siswa, (Bandung: PT Remaja Rosdakarya, 2016) Hlm. 289.
} 
Berdasarkan uraian di atas, berkaitan dengan masalah yang terjadi yaitu rendahnya Motivasi belajar siswa di SMPI Nurul Yaqin Bujur Timur Batu Marmar Pamekasan. Ada beberapa indikator dari ketidak antusiasme siswa dalam proses pembelajaran diantaranya sering keluar waktu KBM berlangsung, dan tidak masuk sekolah ketika tidak menyukai terhadap pembelajaran tersebut. Hal ini merupakan masalah, yang perlu adanya penanganan dari seorang guru. Yang mana guru-guru dari berbagai mata pelajaran diharuskan untuk mengolah strategi sehingga siswa-siswi di SMPI Nurul Yaqin bisa memiliki Motivasi belajar yang tinggi.

Adapun yang penulis temukan di SMPI Nurul Yaqin Bujur Timur Batu Marmar Pamekasan, ada beberapa mata pelajaran yang ditanamkan nilai-nilai didalamnya untuk memberikan motivasi oleh seorang guru terhadap siswa, diantaranya pada pembelajaran IPS. Dimana pada pembelajaran IPS siswa merasa senang dalam menerima pelajaran, dalam hal ini setelah penulis amati pada beberapa siswa, yang menyebabkan siswa termotivasi untuk terus belajar, akibat adanya antusiasme guru yaitu pemberian Reward. $^{6}$

Demikian dari aspek-aspek yang dipaparkan tersebut yang menjadi dasar penelitian ini adalah adanya Motivasi belajar siswa di SMPI Nurul Yaqin Bujur Timur Batu Marmar Pamekasan. Maka muncul pemikiran untuk mengadakan suatu penelitian dengan judul "Pengaruh Pemberian Reward Terhadap Motivasi Belajar Siswa Pada Pembelajaran IPS Di SMPI Nurul Yaqin Bujur Timur Batu Marmar Pamekasan". Sehingga dengan judul penelitian ini, akan diketahui besar kecilnya pengaruh pemberian Reward terhadap Motivasi belajar pada pembelajaran IPS di SMPI Nurul Yaqin Bujur Timur Batu Marmar Pamekasan.

\section{METODE PENELITIAN}

Penelitian ini menggunakan pendekatan kuantitatif artinya dalam penelitian ini analisis data yang digunakan adalah analisis data statistik. Sedangkan sifatnya adalah Korelasional yaitu mencari hubungan antara satu variabel dengan variabel yang lain

Penelitian yang peneliti lakukan merupakan penelitian populasi (Populasi Research). ${ }^{7}$ Sampel yang diambil dalam penelitian ini adalah semua siswa-siswi SMPI Nurul Yaqin yang berjumlah 45 siswa.

\footnotetext{
${ }^{6}$ Yuliana, Wawancara, Bujur Timur, 10-September-2018

${ }^{7}$ Tim Revisi, Pedoman Penulisan Karya Ilmiah, (Pamekasan: STAIN Press, 2015), hlm. 13
}

Ketentuan ini didasarkan atas pendapat Suharsimi Arikunto, yang menyatakan "maka apabila subjeknya kurang dari 100 , lebih baik diambil semua sehingga penelitiannya merupakan penelitian populasi. ${ }^{8}$

$$
r_{x y}=\frac{\sum x y}{\sqrt{\left(\sum x^{2}\right)\left(\sum y^{2}\right)}}
$$

Instrumen dari penelitian ini dengan menggunakan angket, observasi dan dokumentasi dan uji validitas dan reliabelitas dari angket dengan menggunakan aplikasi SPSS. Setelah pengumpulan data dilakukan yaitu dengan cara menggunakan angket langkah selanjutnya menganalisis data secara manual dengan menggunakan analisis Product Moment dengan rumus

Untuk mengetahui kebenaran hipotesis yang telah diajukan, maka akan dilakukan dengan jalan membandingkan $r$ kerja dengan table korelasi

Product Moment
\begin{tabular}{|c|c|}
\hline Nilai & Interpretasi \\
\hline $0.90-1.00$ & Sangat Tinggi \\
\hline $0.70-0.90$ & Tinggi \\
\hline $0.40-0.70$ & Cukup \\
\hline $0.20-0.40$ & Rendah \\
\hline $0.00-0.20$ & Sangat Rendah \\
\hline
\end{tabular}

Dan Harga Kritik "r" Product Moment

\begin{tabular}{|c|c|c|}
\hline \multirow{2}{*}{$\mathrm{N}$} & \multicolumn{2}{|c|}{ Interval Kepercayaan } \\
\cline { 2 - 3 } & $5 \%$ & $1 \%$ \\
\hline 45 & 0,288 & 0,372 \\
\hline
\end{tabular}

\section{Hasil Pembahasan}

Pengaruh pemberian Reward terhadap Motivasi belajar siswa pada pembelajaran IPS di SMPI Nurul Yaqin Bujur Timur Batu Marmar Pamekasan ada pengaruh.

Reward merupakan salah satu alat untuk meningkatkan Motivasi para peserta didik. ${ }^{9}$ Reward yang diberikan oleh guru atas hal positif yang dilakukan oleh siswa. Hal tersebut guru bermaksud membuat anak lebih giat usahanya untuk bekerja dan berbuat lebih baik lagi. Kurangnya guru dalam memberikan Reward pada siswa akan menimbulkan kejenuhan dalam melakukan kegiatan belajar. ${ }^{10}$ Reward dalam penelitian ini meliputi

\footnotetext{
${ }^{8}$ Suharsimi Arikunto, Prosedur Penelitian Suatu Pendekatan Praktek (Jakarta: PT Renika Cipta, 2006) hlm. 107

9 Kompri, Motivasi Pembelajaran Perspektif Guru dan Siswa, (Bandung: PT Remaja Rosdakarya, 2016) HIm. 289.

${ }_{10}$ Risky Ardi Mabruri, Pengaruh Pemberian Reward terhadap Motivasi Belajar IPA Siswa Kelas IV SD Muhammadiyah Piyaman, Jurnal Pendidikan Guru
} 
empat indikator yakni pujian, nilai, pengakuan dan mengingat nama. Hal tersebut sejalan dengan pendapat Wahid Murni, yang mengemukakan bahwa penggunaan Reward yang berupa benda hendaknya tidak mengarah pada benda tersebut sebagai tujuan belajar anak, sehinnga perlu dibatasi penggunaannya.

Adapun Motivasi Belajar merupakan dua hal yang saling mempengaruhi. Namun, sebelum membahas lebih jauh tentang Motivasi belajar maka perlulah dibedakan dahulu antara pengertian Motivasi dan pengertian belajar. Istilah Motivasi berasal dari kata Motif yang dapat diartikan sebagai kekuatan yang terdapat dalam diri individu, yang menyebabkan individu tersebut bertindak atau berbuat. Motif adalah daya penggerak dalam diri seseorang untuk melakukan aktivitas tertentu demi mencapai tujuan tertentu. Dengan demikian Motivasi merupakan dorongan yang terdapat dalam diri seseorang untuk berusaha mengadakan perubahan tingkah laku yang lebih baik dalam memenuhi kebutuhannya.

Sedangkan istilah belajar menurut Slameto adalah suatu proses usaha yang dilakukan seseorang untuk memperoleh suatu perubahan tingkah laku yang baru secara keseluruhan sebagai pengalamannya sendiri dalam interaksi dengan lingkungannya. Berdasarkan penjelasan tentang pengertian Motivasi dan belajar tersebut maka dapat dikemukakan pengertian Motivasi belajar adalah keseluruhan daya penggerak psikis di dalam diri peserta didik yang menimbulkan kegiatan belajar, menjamin kelangsungan kegiatan belajar dan memberikan arah pada kegiatan belajar. ${ }^{11}$

Berdasarkan pengertian diatas dapat disimpulkan bahwa Motivasi dapat dipandang sebagai daya penggerak dari dalam diri individu untuk melakukan aktivitas tertentu dalam mencapai tujuan. Motivasi dipandang dari segi proses, berarti Motivasi dapat dirangsang oleh faktor luar untuk menimbulkan motivasi dalam diri peserta didik.

Berkaitan dengan pembelajaran IPS yang teintegrasi dari beberapa ilmu diantaranya ilmu Sosiologi, Ekonomi, Sejarah dan Geografi maka perlu seorang guru untuk memotivasi siswa untuk terus belajar . karena aktivitas dalam pembelajaran IPS di kelas yang melibatkan siswa agar mereka memiliki

Sekolah Dasar Edisi 32 Tahun ke-5 2016, Universitas Negeri Yogyakarta.

${ }^{11}$ Yusvidha Ernata, Analisis Motivasi Belajar Peserta didik melalui Pemberian Reward dan Punishment di SDN Ngaringan 05 Kec. Gandusari Kab. Blitar, IKIP Budi Utomo Malang, Jurnal Pemikiran dan pengembangan SD, Volume 5, Nomer 2, September 2017. kepekaan sosial. Rangsangan berupa Pemberian Reward dilakukan di SMPI Nurul Yaqin, supaya siswa bisa merasakan toleransi antar guru, sehingga dalam hal ini juga membantu membangun Motivasi untuk terus belajar khususnya pada pembelajaran IPS di SMPI Nurul Yaqin. Salah satu bentuk yang dilakukan guru IPS dalam memberikan Reward di SMPI Nurul Yaqin yaitu pada materi, Flora dan Fauna di Indonesia kelas VII, kelas VIII Mobilitas Sosial dan kelas IX perubahan sosial budaya.

Selanjutnya dari pembahasan diatas mengenai Reward dapat memberikan pengaruh yang positif terhadap Motivasi belajar siswa pada pembelajaran IPS di SMPI Nurul Yaqin. Hal tersebut juga dapat dibuktikan setelah dilakukan analisis data angket sebagaimana yang telah disebut di atas ternyata menunjukkan hasil positif, karena nilai " $r$ " kerja sebesar 0,418 lebih besar dari nilai "r" tabel product moment, baik dalam interval kepercayaan $5 \%(0,288)$ maupun $1 \%$ $(0,372)$ pada $N=45$. Demikian nilai " $r$ " kerja sebesar 0,418 berada diantara angka 0,40 0,70 dengan interpretasi cukup.

Demikian pembahasan tentang pengaruh pemberian Reward terhadap Motivasi belajar siswa pada pembelajaran IPS di SMPI Nurul Yaqin Bujur Timur Batu Marmar Pamekasan. Setelah dibandingkan data angket sebagaimana yang telah disebut di atas ternyata menunjukkandan dipadukan antara kajian teori dengan hasil penelitian maka dapat disimpulkan pemberian Reward ada pengaruh terhadap Motivasi belajar

Siswa pada pembelajaran IPS di SMPI Nurul Yaqin Bujur Timur Batu Marmar Pamekasan dengan interpretasi cukup. Dalam hal ini dibuktikan dengan hasil nilai matapelajaran IPS dan hasil pengamatan yang telah dilakukan penulis terhadap siswa dan guru IPS. Karena dengan pemberian Reward siswa SMPI Nurul Yaqin memiliki Motivasi untuk belajar.

\section{PENUTUP}

Dari hasil penelitian yang dilakukan, dapat disimpulkan bahwa:

Pertama Ada pengaruh pemberian Reward terhadap Motivasi belajar siswa pada pembelajaran IPS di SMPI Nurul Yaqin Bujur Timur Batu Marmar Pamekasan. Hal ini terbukti dengan lebih besarnya harga $r$ kerja dibandingkan dengan harga $r$ tabel, yakni perbandingan antara 0,418 dengan 0,288 dan 0,372 masing-masing interval kepercayaan 5\% dan $1 \%$.

Kedua Pengaruh pemberian Reward terhadap Motivasi belajar siswa pada 
pembelajaran IPS di SMPI Nurul Yaqin Bujur Timur Batu Marmar Pamekasan berada pada kategori cukup. Hal ini terbukti dari hasil konsultasi harga $r$ kerja dengan interpretasi korelasi Product Moment, yang menyatakan bahwa harga $r$ kerja $(0,418)$ berada pada rentang nilai antara $0,40-0,70$ dengan pengertian bahwa kedua variabel tersebut terdapat korelasi yang cukup.

\section{DAFTAR PUSTAKA}

Arikunto, Suharsimi. 2006. Prosedur Penelitian Suatu Pendekatan Praktek, Jakarta: PT Renika Cipta.

Ernata, Yusvidha. Analisis Motivasi Belajar Peserta didik melalui Pemberian Reward dan Punishment di SDN Ngaringan $05 \mathrm{Kec}$. Gandusari Kab. Blitar, IKIP Budi Utomo Malang, Jurnal Pemikiran dan pengembangan SD, Volume 5, Nomer 2, September 2017.

Hartono, Rudi. 2014. Ragam Model Mengajar yang Mudah Diterima Murid, Jogjakarta: Diva Press.
Ilahi, Muhammad takdir. 2012. Revitalisasi Pendidikan Berbasis Moral, Jogjakarta: Ar-Ruzz Media.

Kompri. 2016. Motivasi Pembelajaran Perspektif Guru dan Siswa, Bandung: PT Remaja Rosdakarya.

Mabruri Risky Ardi. Pengaruh Pemberian Reward terhadap Motivasi Belajar IPA Siswa Kelas IV SD Muhammadiyah Piyaman, Jurnal Pendidikan Guru Sekolah Dasar Edisi 32 Tahun ke-5 2016, Universitas Negeri Yogyakarta.

Rusman. 2014. Model-model Pembelajaran, Jakarta: Rajawali Pers.

Solichin, H. M. Muchlis. 2016. Psikologi Pendidikan Berparadigma Konstruktivistik. Surabaya: CV Salsabila Putra Pratama.

Tim Revisi. 2015. Pedoman Penulisan Karya IImiah, Pamekasan: STAIN Press, Yuliana, Wawancara, Bujur Timur, 10September-2018. 